Supporting Information

\title{
Effect of relative humidity on secondary brown carbon formation
}

\section{in aqueous droplets}

Nethmi Y. Kasthuriarachchi ${ }^{1}$, Laura-Hélèna Rivellini ${ }^{2}$, Xi Chen ${ }^{3}$, Yong Jie Li ${ }^{3}$

and Alex K. Y. Lee ${ }^{*}, 1,2, a$

${ }^{1}$ Department of Civil and Environmental Engineering, National University of Singapore, Singapore

${ }^{2}$ NUS Environmental Research Institute, National University of Singapore, Singapore

${ }^{3}$ Department of Civil and Environmental Engineering, Faculty of Science and Technology, University of Macau, Macau, China

${ }^{a}$ now at: Air Quality Processes Research Section, Environment and Climate Change Canada, Canada

*Correspondence to: Alex K. Y. Lee (alex.lee@canada.ca)

\section{Contents}

Number of pages: 11

S1: Liquid water content and solute concentrations in evaporating droplets

S2: Mass spectral features of nitrogen-containing organics formed in evaporated droplets

Figures: 5

References: 11 


\section{S1. Liquid water content and solute concentrations in evaporating droplets}

The role of liquid water content and hyrgroscopic properties of levitated particles containing glyoxal with ammonium sulfate or amino acids (glycine and alanine) were investigated using an electrodynamic balance (EDB) in a collaborative study. ${ }^{1}$ The EDB experiments showed the change in the mass growth factor (MGF) of glyoxal and ammonium sulfate/glycine/alanine mixed particles with RH (Figure S2). Using this MGF and the initial solute concentrations, we estimate the liquid water content (LWC) and solute concentrations of droplets at different RH conditions. Here we assume that the reactants do not volatilise and that the molecular ratio of reactants remain the same with drying (i.e. the amount of solute and the ratio of each reactant in the droplet at the initial condition remains the same throughout all $\mathrm{RH}$ conditions). Note that the same molecular ratio of reactants were used in the two studies. The calculated LWC and solute concentrations at each $\mathrm{RH}$ level are shown in Figure 4 and $\mathrm{S} 3$. Based on these assumptions, we note that the solute concentrations reported here represent an upper limit for molar concentrations in the aerosols. 


\section{S2. Mass spectral features of nitrogen-containing organics formed in evaporated droplets}

Variation of nitrogen-containing organic species formation at different $\mathrm{RH}$ conditions were investigated using a high resolution aerosol mass spectrometer (HR-AMS) connected to the existing experimental setup (Figure S5), just before the filter. A constant RH was maintained for 10 minutes and the AMS measured the non-refractory particulate mass concentration at every minute. Mass spectra of nitrogen containing organic fragments $\left(\mathrm{C}_{\mathrm{x}} \mathrm{H}_{\mathrm{y}} \mathrm{N}_{\mathrm{p}}{ }^{+}\right.$and $\mathrm{C}_{\mathrm{x}} \mathrm{H}_{\mathrm{y}} \mathrm{O}_{\mathrm{z}} \mathrm{N}_{\mathrm{p}}^{+}$) of the four chemical systems are shown in Figure S5. All mass spectra were normalised by the total organic aerosol intensity measured by the AMS at the respective RH conditions. Note that due to the hard ionisation technique employed by the AMS (electron impact ionisation), most species are detected as ion fragments.

The spectra for glyoxal and ammonium sulfate reactions match well with the mass spectra measured by Lee et al. ${ }^{2}$ in evaporating droplets for the same reactions. Imidazole and secondary imidazole products such as imidazole-2-carboxaldehyde and 2,2'-biimidazole and their derivatives have been identified as major nitrogen-containing organic products of glyoxal and ammonium sulfate reactions and they have been recognised as major contributing species to the observed light absorbance. ${ }^{3-5}$ The relatively strong signals at $m / z, 41\left(\mathrm{C}_{2} \mathrm{H}_{3} \mathrm{~N}^{+}\right)$and 68 $\left(\mathrm{C}_{3} \mathrm{H}_{4} \mathrm{~N}_{2}{ }^{+}\right)$have been identified as ion fragments from imidazole $\left(\mathrm{C}_{3} \mathrm{H}_{4} \mathrm{~N}_{2}\right)$ and imidazole derivatives that may be responsible for the absorbance $\sim 207 \mathrm{~nm}$. The minor peak detected at $\mathrm{m} / \mathrm{z}, 96$ may result from the contribution of imidazole-2-carboxyaldehyde (molecular weight 96), which is known to absorb at $277 \mathrm{~m}$. Galloway et al. $^{4}$ has shown that imidazole-2carboxyaldehyde can also be significant source for the peak at $m / z 68$. Other major peaks at $\mathrm{m} / \mathrm{z}, 58$ and $\mathrm{m} / \mathrm{z}, 73$ may be tentatively assigned to fragments of imines formed as intermediate products between glyoxal and ammonia reactions. Mass spectral features of methylglyoxal and ammonium sulfate reactions were somewhat similar to that of glyoxal reactions. Imine 
intermediates or fragments of the numerous $\mathrm{C}_{x} \mathrm{H}_{y} \mathrm{O}_{z} \mathrm{~N}_{p}$ species that have been previously detected in this reaction systems may contribute to the relatively stronger peak at $\mathrm{m} / \mathrm{z}, 44$ $\left(\mathrm{CH}_{2} \mathrm{NO}^{+}\right) .{ }^{6,7}$ Note that the intensity of the overall signals were lower than that of glyoxal and ammonium sulfate reaction system. Mass spectra of glycine reactions were dominated by major $\mathrm{C}_{\mathrm{x}} \mathrm{H}_{\mathrm{y}} \mathrm{N}_{\mathrm{p}}{ }^{+}$peaks in the $\mathrm{m} / z, 25$ to $\mathrm{m} / z, 30$ range, while all other peaks were almost an order of magnitude smaller. Since pure glycine itself can have significant contribution to N-containing fragments, we do not elaborate on the mass spectra from these reaction systems.

High resolution analysis was used to calculate the elemental composition for the four reactions systems. ${ }^{8}$ Nitrogen $(\mathrm{N})$ to carbon $(\mathrm{C})$ ratio was used as proxy for $\mathrm{N}$-containing organic species formation at different RH conditions. Figure 1 and 2 in the main text shows the average $\mathrm{N}: \mathrm{C}$ variation with $\mathrm{RH}$ for glyoxal (e) and methylglyoxal (f) reactions with ammonium sulfate and glycine, respectively. Note that the ammonium related fragments were removed from the fit. The N:C for pure glycine was $0.46( \pm 0.005)$, which is approximately $8 \%$ lower than its theoretical value of 0.5 , indicating that our $\mathrm{N}: \mathrm{C}$ values may be slightly underestimated. The average N:C of pure glyoxal and methylglyoxal were $0.044( \pm 0.002)$ and $0.045( \pm 0.012)$, respectively. For the ammonium sulfate reactions, the $\mathrm{N}: \mathrm{C}$ at $\mathrm{RH}>75 \%$ were within the same range as that of the pure compounds and increased with reducing $\mathrm{RH}$, indicating the formation of additional $\mathrm{N}$-containing organics in dryer conditions. The $\mathrm{N}: \mathrm{C}$ of the glycine reactions were all lower than that of pure glycine, which is consistent with the previous observations of disubstituted-imidazole formation. ${ }^{9}$ The variation of the N:C with $\mathrm{RH}$ and its implications are discussed in detail in section 3.3 in the main text. 

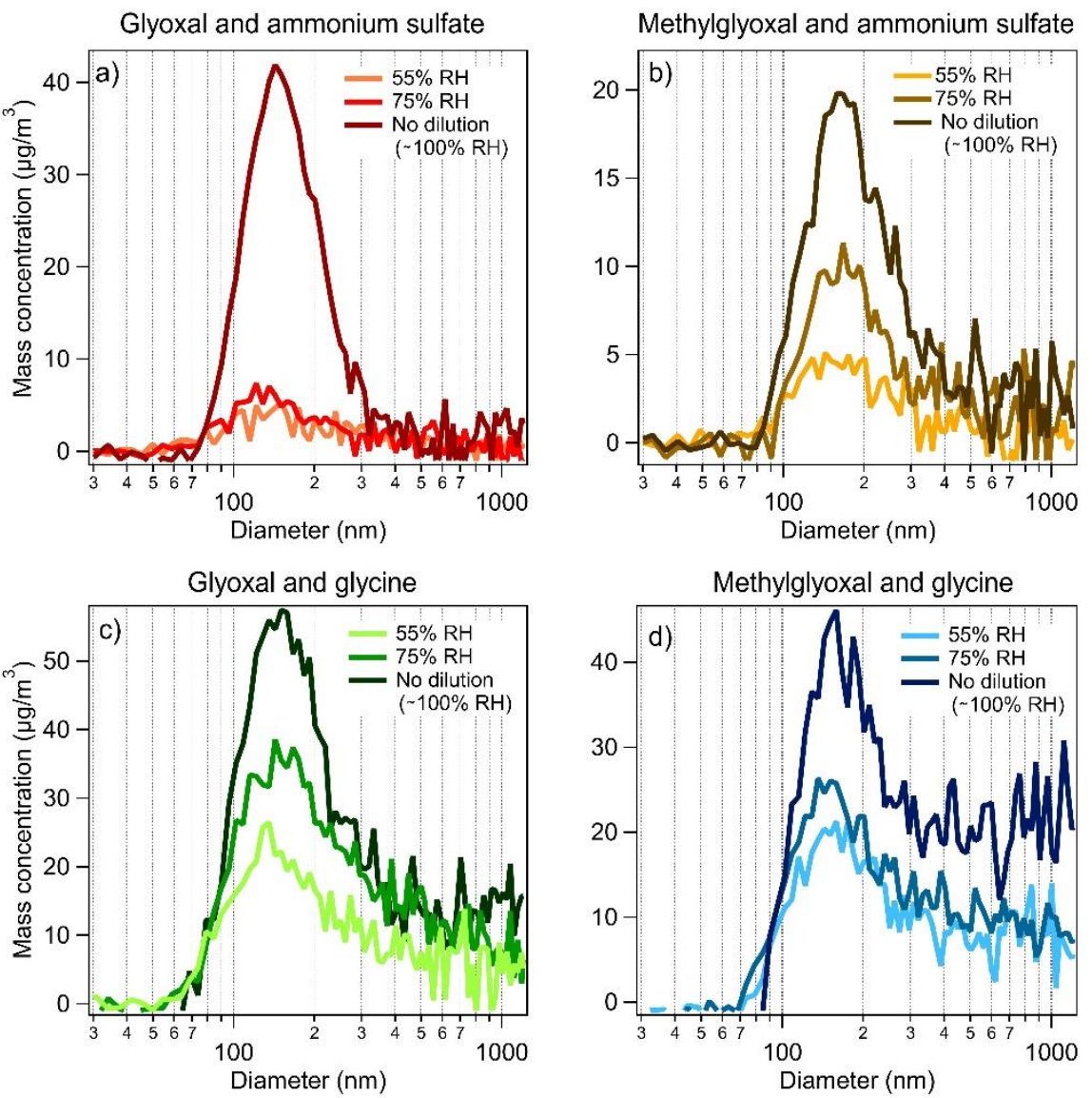

Figure S1: Size distribution of organic aerosols (OA) from glyoxal and methylglyoxal reactions with ammonium sulfate ( $\mathrm{a}$ and $\mathrm{b}$ ) and glycine (c and d) at 55\%, 75\% and 100\% RH (i.e. with no dilution) from HR-AMS measurements. Note that the AMS measures the vacuum aerodynamic diameter of particles. 

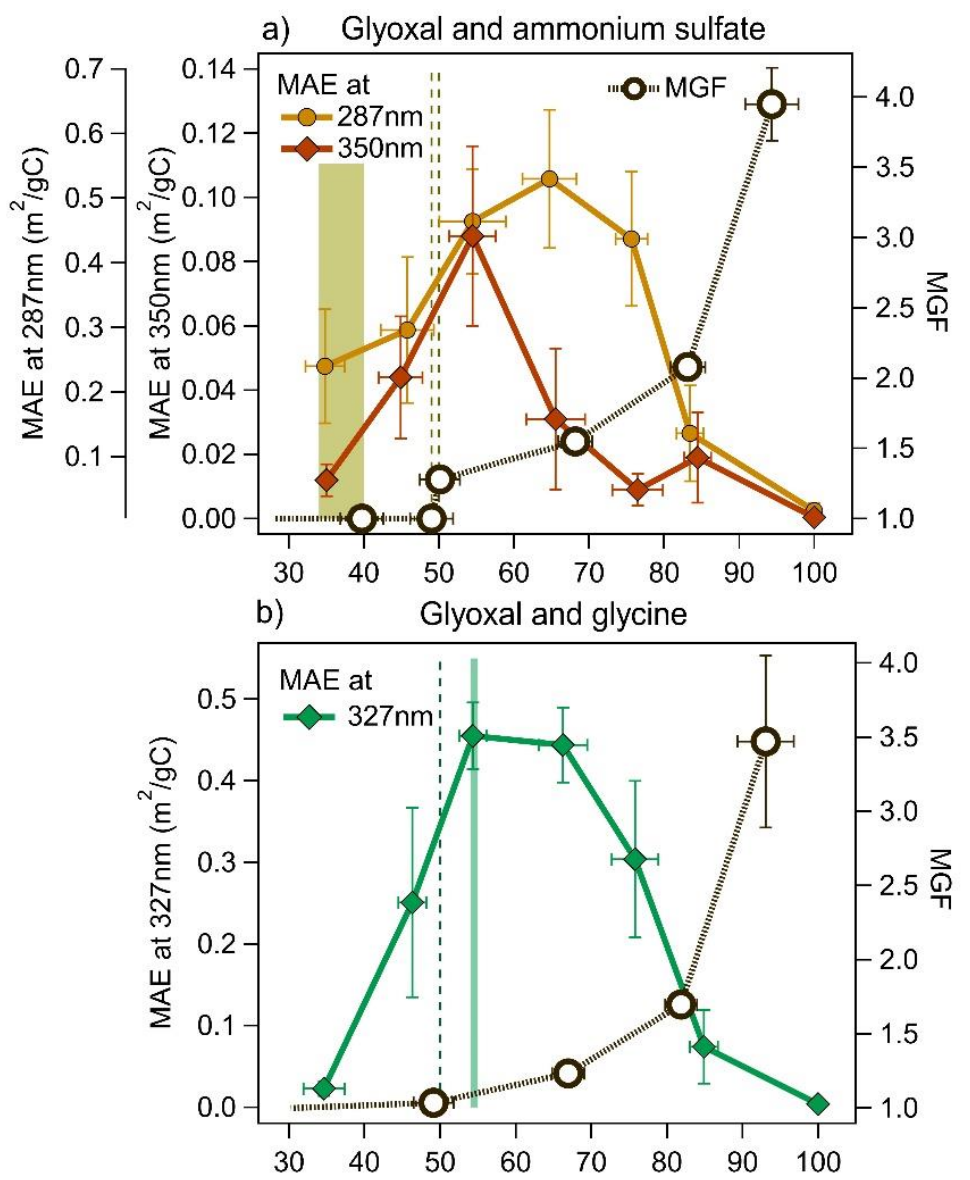

c)

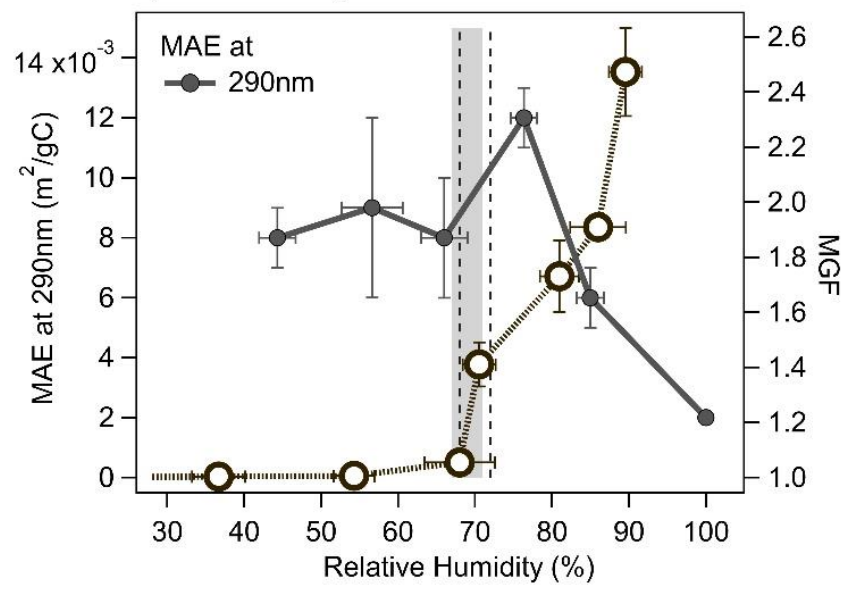

Figure S2: Variations of the average mass growth factor $(\mathrm{MGF})^{1}$ and MAE with RH for reactions of glyoxal with a) ammonium sulfate (MAE at 287nm and 350nm), b) glycine (MAE at $330 \mathrm{~nm}$ ) and c) alanine (MAE at 290nm). Average MAE values are presented for each $10 \%$ RH bin width. Error bars represent one standard deviation for both MAE and MGF. The shaded RH region represent the crystallisation $\mathrm{RH}(\mathrm{CRH})$ for pure compounds. ${ }^{10,11}$ The dashed lines represent the measured $\mathrm{CRH}$ regions for glyoxal + ammonium sulfate/glycine/alanine mixed particles from Chen et al.. ${ }^{1}$ 
Glyoxal and alanine
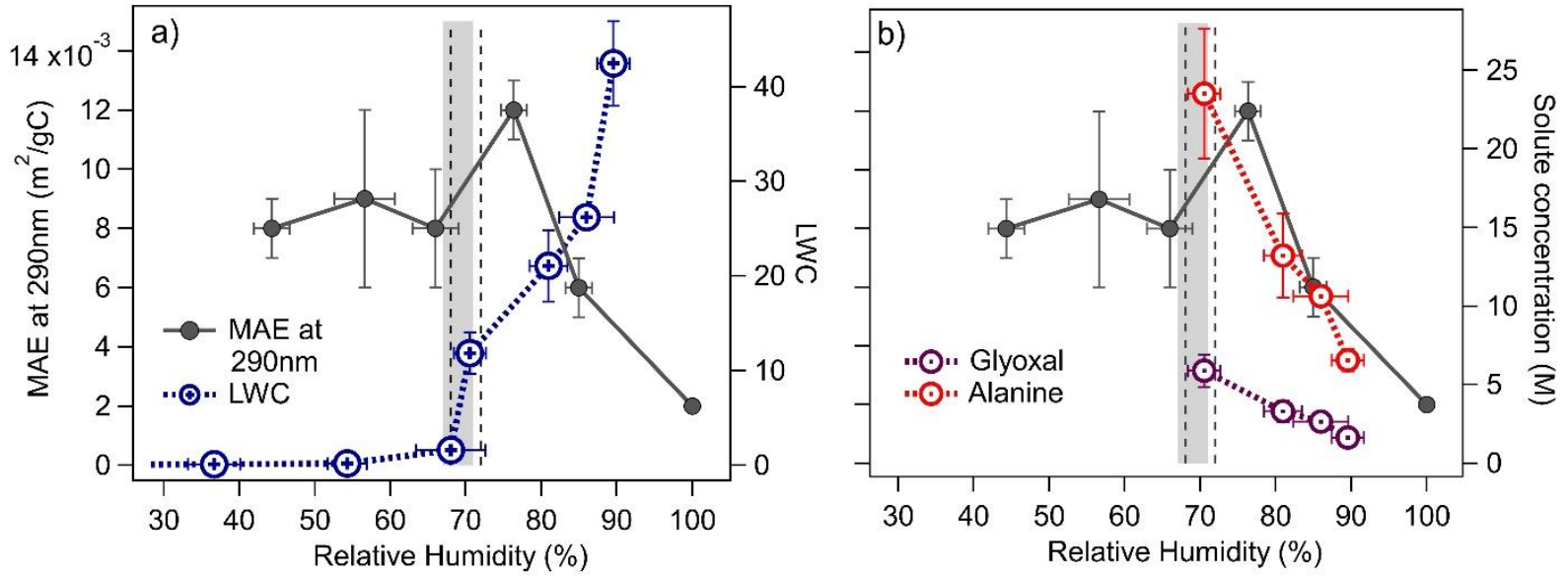

Figure S3: Variations of average a) liquid water content (LWC, represented in moles of water per unit mole of each reactant), b) solute concentrations and MAE (at 290nm) with RH for reactions of glyoxal with alanine. MAE values are averaged over each $10 \% \mathrm{RH}$ bin width. Error bars represent one standard deviation. The shaded RH region represent the crystallisation $\mathrm{RH}(\mathrm{CRH})$ for pure alanine ${ }^{11}$ and the dashed lines represent the measured CRH regions for glyoxal + alanine mixed particles from Chen et al.. ${ }^{1}$ 


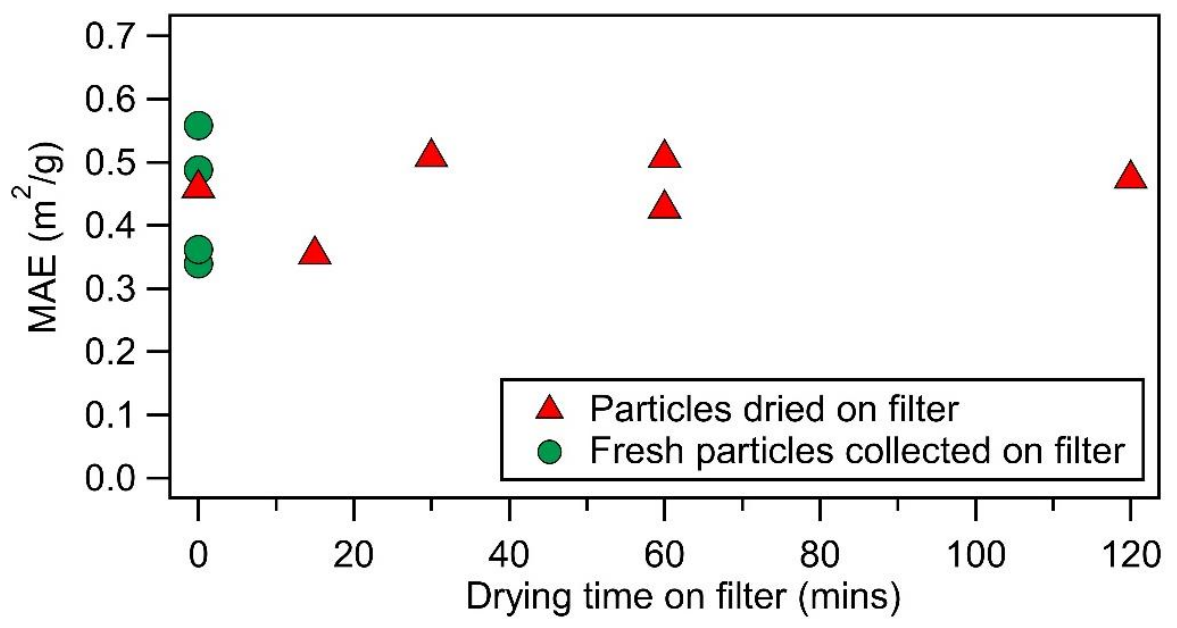

Figure S4: Variation of MAE of particles collected at 70-80\% RH for one hour then dried on the filter by purging dry air for 15 minutes to 2 hours from reactions of glyoxal with ammonium sulfate. The MAE of fresh particles that were collected at the same RH range (i.e. collected on the filter for 2 hours at a specific RH condition within the 70-80\% RH range) are shown in green for comparison. 
a) Glyoxal + Ammonium sulfate

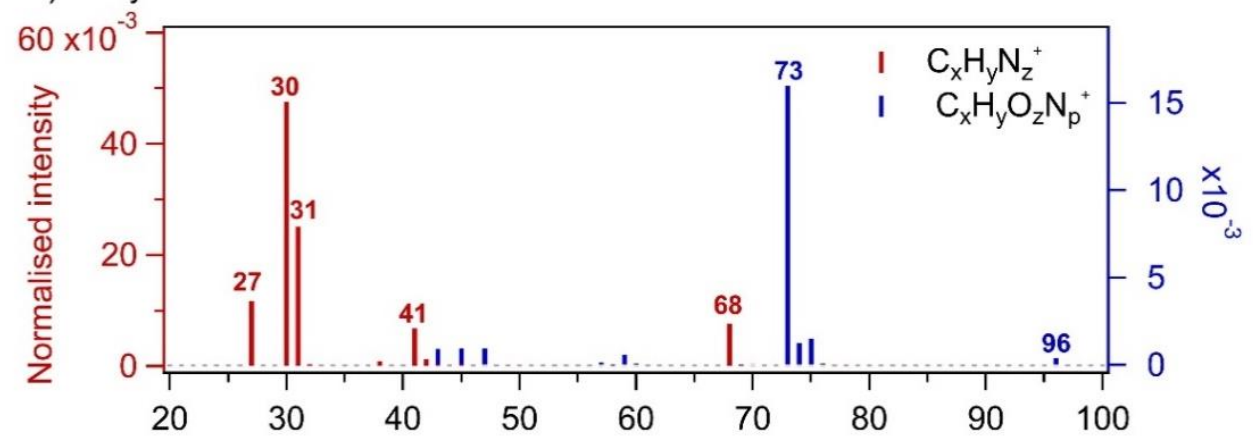

b) Methylglyoxal + Ammonium sulfate

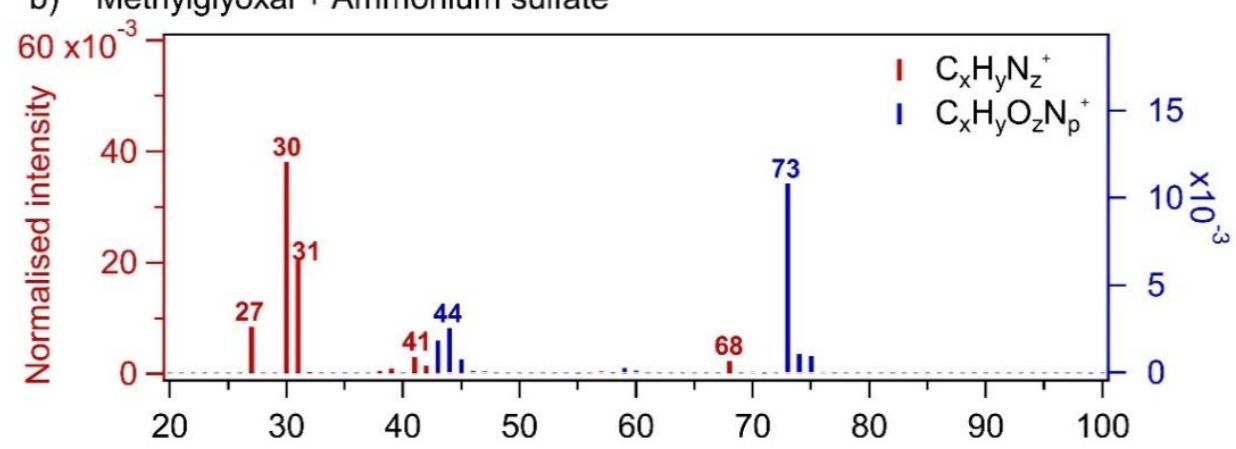

c) Glyoxal + Glycine

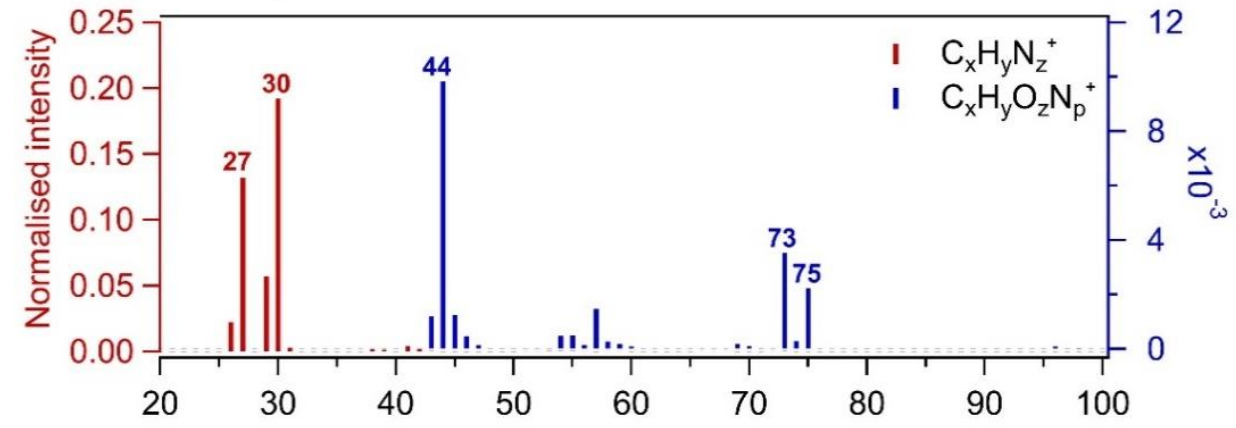

d) Methylglyoxal + Glycine

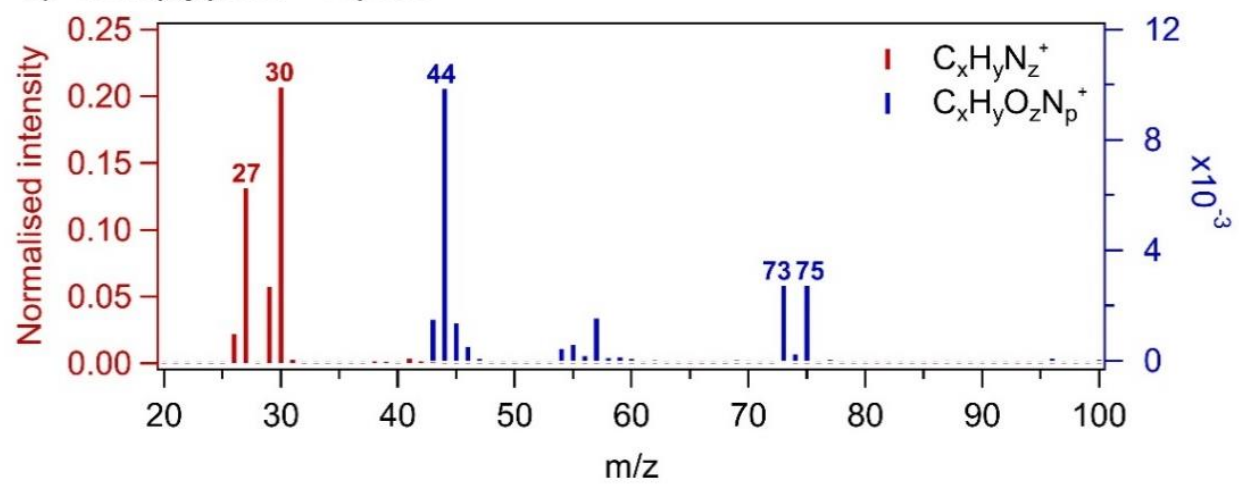

Figure S5: The mass spectra (nitrogen-containing organic fragments only) of evaporated droplets a) glyoxal and ammonium sulfate and b) methylglyoxal and ammonium sulfate at 55\% $\mathrm{RH}, \mathrm{c})$ glyoxal and glycine and d) methylglyoxal and glycine at $65 \% \mathrm{RH}$. 


\section{REFERENCES}

(1) Chen, X.; Chu, Y.; Lee, A. K. Y.; Gen, M.; Kasthuriarachchi, N. .; Chan, C. K.; Li, Y. J. Relative Humidity History Affects Hygroscopicity of Mixed Particles of Glyoxal and Reduced Nitrogenous Species. Environ. Sci. Technol. 2020, 54 (12), 7097-7106.

(2) Lee, A. K. Y.; Zhao, R.; Li, R.; Liggio, J.; Li, S. M.; Abbatt, J. P. D. Formation of Light Absorbing Organo-Nitrogen Species from Evaporation of Droplets Containing Glyoxal and Ammonium Sulfate. Environ. Sci. Technol. 2013, 47 (22), 12819-12826. https://doi.org/10.1021/es402687w.

(3) Yu, G.; Bayer, A. R.; Galloway, M. M.; Korshavn, K. J.; Fry, C. G.; Keutsch, F. N. Glyoxal in Aqueous Ammonium Sulfate Solutions: Products, Kinetics and Hydration Effects. Environ. Sci. Technol. 2011, $45 \quad$ (15), 6336-6342. https://doi.org/10.1021/es200989n.

(4) Galloway, M. M.; Chhabra, P. S.; Chan, A. W. H.; Surratt, J. D.; Flagan, R. C.; Seinfeld, J. H.; Keutsch, F. N. Glyoxal Uptake on Ammonium Sulphate Seed Aerosol: Reaction Products and Reversibility of Uptake under Dark and Irradiated Conditions. Atmos. Chem. Phys. 2009, 9, 3331-3345.

(5) Kampf, C. J.; Jakob, R.; Hoffmann, T. Identification and Characterization of Aging Products in the Glyoxal/Ammonium Sulfate System - Implications for Light-Absorbing Material in Atmospheric Aerosols. Atmos. Chem. Phys. 2012, 12 (14), 6323-6333. https://doi.org/10.5194/acp-12-6323-2012.

(6) Lin, P.; Bluvshtein, N.; Rudich, Y.; Nizkorodov, S. A.; Laskin, J.; Laskin, A. Molecular Chemistry of Atmospheric Brown Carbon Inferred from a Nationwide Biomass Burning Event. Environ. Sci. Technol. 2017, $51 \quad$ (20), 11561-11570. https://doi.org/10.1021/acs.est.7b02276. 
(7) Sareen, N.; Shapiro, E. L.; Schwier, A. N.; McNeill, V. F. Secondary Organic Material Formed by Methylglyoxal in Aqueous Aerosol Mimics. Atmos. Chem. Phys. 2010, 10, 997-1016. https://doi.org/10.5194/acpd-9-15567-2009.

(8) Aiken, A. C.; DeCarlo, P. F.; Jimenez, J. L. Elemental Analysis of Organic Species with Electron Ionization High-Resolution Mass Spectrometry. Anal. Chem. 2007, 79 (21), 8350-8358. https://doi.org/10.1021/ac071150w.

(9) Trainic, M.; Abo Riziq, A.; Lavi, A.; Rudich, Y. Role of Interfacial Water in the Heterogeneous Uptake of Glyoxal by Mixed Glycine and Ammonium Sulfate Aerosols. J. Phys. Chem. A 2012, 116 (24), 5948-5957. https://doi.org/10.1021/jp2104837.

(10) Onasch, T. B.; Siefert, R. L.; Brooks, S. D.; Prenni, A. J.; Murray, B.; Wilson, M. A.; Tolber, M. A. Infrared Spectroscopic Study of the Deliquescence and Efflorescence of Ammonium Sulfate Aerosol as a Function of Temperature. J. Geophys. Res. 1999, 104, $21317-21326$.

(11) Chan, M. N.; Choi, M. Y.; Ng, N. L.; Chan, C. K. Hygroscopicity of Water-Soluble Organic Compounds in Atmospheric Aerosols: Amino Acids and Biomass Burning Derived Organic Species. Environ. Sci. Technol. 2005, 39 (6), 1555-1562. https://doi.org/10.1021/es0495841. 